\section{Arzt und Armee}

Der Armee fehlen Militärärzte. Jeder der in den letzten zwei Jahrzehnten militärische Kurse oder Übungen zur organisieren hatte, kennt diese chronische Schwachstelle. Die Gründe dafür sind mannigfaltig. Der Wertewandel in der Gesellschaft hat Kaderprobleme in der ganzen Armee verursacht. "Der Soldate, der Soldate ist nicht mehr der schönste Mann im Staate!» Im Sanitätsdienst kommt hinzu, dass die Absicht, Medizinstudium und Weiterbildung mit der Militärarztlaufbahn in Einklang und in einen vernünftigen Zeitrahmen zu bringen, für die Betroffenen ein schwieriges Unterfangen geworden ist, ein Unterfangen, das manchen Verzicht verlangt. Kompensatorische Anreize sind bisher zu zaghaft oder gar nicht geschaffen worden.

Dem Medizinstudenten kommen Semester- und Prüfungstermine mit den militärischen Schulen und Kursen in die Quere, der Assistenzarzt mit militärischen Ambitionen hat zunehmend das Nachsehen auf der Suche nach geeigneten Weiterbildungsstellen. Die organisatorische und wirtschaftliche Belastung des Stellenetats der Spitäler durch Militärdienstpflichtige ist zu einem prioritären Auswahlkriterium geworden.

Auf der fachlichen Ebene fehlen die Anreize da, wo die im Militärdienst erworbenen fachlichen Kompetenzen für die Berufsbildung weder Anerkennung noch Anrechnung finden.

Den niedergelassenen Ärzten hat der Staat mit seinen immer schärferen Eingriffen in die ärztliche Berufsausübung und mit seiner Tarifpolitik, die der Kostenentwicklung des Kleinunternehmens Arztpraxis längst nicht mehr Rechnung trägt, die Motivation und die finanziellen Reserven für ein über die schiere Pflicht hinausgehendes Engagement in der Armee bereits weitgehend zerstört. Gerade unter denjenigen
Kollegen, die immer wieder bereit waren, dem Gemeinwesen Mehrwert zu bieten, machen sich Staatsverdrossenheit und Motivationsschwund breit. Die Armee hat dazu ihren Teil beigetragen. Zwar auf Rechtsgrundlagen gestützt, aber eben "manu militari» hat sie, um dem Militärarztmangel palliativ zu begegnen, altgediente Sanitätsoffiziere zu zusätzlichen Diensttagen verknurrt. Das fördert die Gefolgschaft nicht.

Das Resultat dieser Entwicklung ist blamabel: Gerade zehn Prozent der jährlichen Studienabgänger können für die Ausbildung zum Militärarzt gewonnen werden. Und die Bereitschaft, in höheren Kaderfunktionen zu dienen, schwindet.

Das Armeeleitbild XXI und die Revision des Militärgesetzes, die bis am 31. Juli 2001 in der Vernehmlassung waren, lassen befürchten, dass diese Zustände fortgeschrieben werden. Die Verkürzung der allgemeinen Dienstleistungspflicht verschärft die Probleme zusätzlich.

Dass die Sanität als eigenständige Truppengattung abgeschafft werden und in den Logistiktruppen aufgehen soll, hat in der Ärzteschaft heftige Reaktionen ausgelöst. Dieses Ansinnen steht in diametralem Gegensatz zu den Bedürfnissen der Patienten, zu den Aufgaben des koordinierten Sanitätsdienstes und zu den Erfordernissen einer hochstehenden Ausbildung des Sanitätspersonals und ist daher inakzeptabel.

Unsere Anliegen und Forderungen an der Schwelle zur Armee XXI liegen auf dem Tisch, aber auch unser Vorschläge, zusammen mit denjenigen der Schweizerischen Medizinischen Interfakultätskommission (SMIFK). Wir erwarten, dass nicht nur die Trainpferde sondern auch die Militärärzte und der Sanitätsdienst in der Ausgestaltung der Armee XXI angemessene Beachtung finden!

Dr. med. Reto Laetsch, Mitglied des Zentralvorstandes der FMH

\title{
Wichtige Mitteilung
}

Gemäss Beschluss des Zentralvorstands der FMH vom 15.9.2001 findet am 25. Oktober 2001 eine Präsidentenkonferenz statt und nicht, wie dies in SÄZ Nr. 37 (S. 1953) angekündigt worden war, eine ausserordentliche Ärztekammer; diese ist auf Dezember verschoben worden. Die Präsidentenkonferenz vom 26. September 2001 ist von dieser Änderung nicht betroffen. Weitere Angaben folgen, siehe auch www.fmh.ch. 